\title{
Identification and characterization of the Non- race specific Disease Resistance 1 (NDR1) orthologous protein in coffee
}

\author{
Jean-Luc Cacas ${ }^{1,4}$, Anne-Sophie Petitot ${ }^{1}$, Louis Bernier ${ }^{2}$, Joan Estevan ${ }^{1}$, Geneviève Conejero ${ }^{3}$, Sébastien Mongrand ${ }^{4}$
} and Diana Fernandez ${ }^{1 *}$

\begin{abstract}
Background: Leaf rust, which is caused by the fungus Hemileia vastatrix (Pucciniales), is a devastating disease that affects coffee plants (Coffea arabica L.). Disadvantages that are associated with currently developed phytoprotection approaches have recently led to the search for alternative strategies. These include genetic manipulations that constitutively activate disease resistance signaling pathways. However, molecular actors of such pathways still remain unknown in C. arabica. In this study, we have isolated and characterized the coffee NDR1 gene, whose Arabidopsis ortholog is a well-known master regulator of the hypersensitive response that is dependent on coiledcoil type R-proteins.

Results: Two highly homologous cDNAs coding for putative NDR1 proteins were identified and cloned from leaves of coffee plants. One of the candidate coding sequences was then expressed in the Arabidopsis knock-out null mutant ndr1-1. Upon a challenge with a specific strain of the bacterium Pseudomonas syringae (DC3000:AvrRpt2), analysis of both macroscopic symptoms and in planta microbial growth showed that the coffee cDNA was able to restore the resistance phenotype in the mutant genetic background. Thus, the cDNA was dubbed CaNDR1a (standing for Coffea arabica Non-race specific Disease Resistance 1a). Finally, biochemical and microscopy data were obtained that strongly suggest the mechanistic conservation of the NDR1-driven function within coffee and Arabidopsis plants. Using a transient expression system, it was indeed shown that the CaNDR1a protein, like its Arabidopsis counterpart, is localized to the plasma membrane, where it is possibly tethered by means of a GPI anchor.

Conclusions: Our data provide molecular and genetic evidence for the identification of a novel functional NDR1 homolog in plants. As a key regulator initiating hypersensitive signalling pathways, CaNDR1 gene(s) might be target (s) of choice for manipulating the coffee innate immune system and achieving broad spectrum resistance to pathogens. Given the potential conservation of NDR1-dependent defense mechanisms between Arabidopsis and coffee plants, our work also suggests new ways to isolate the as-yet-unidentified $R$-gene(s) responsible for resistance to $H$. vastatrix.
\end{abstract}

\section{Background}

The genus Coffea includes about 120 species of subtropi$\mathrm{cal} /$ tropical woody perennial trees and shrubs (family Rubiaceae), of which at least two species are of worldwide agro-economic interest. Nearly $75 \%$ of world coffee production originates from Coffea arabica L., while

\footnotetext{
* Correspondence: diana.fernandez@ird.fr

'UMR 186 - IRD/CIRAD/UM2 Résistance des Plantes aux Bio-agresseurs, Institut de Recherche pour le Développement (IRD), BP64501, 34394 Montpellier Cedex 5, France

Full list of author information is available at the end of the article
}

about $20 \%$ comes from C. canephora Pierre ex A. Froehner $(=C$. robusta). Orange coffee leaf rust is considered to be one of the major plagues affecting C. arabica [1]. The fungus responsible for the disease, Hemileia vastatrix Berkeley \& Broome, is widely spread throughout coffee-growing countries and can cause severe defoliation, resulting in substantial berry yield losses $[1,2]$. Furthermore, the two current approaches for restricting pathogen infection offer limited advantages. First, fungicide application, although cost-effective, does not always result in adequate disease control and, moreover, it has a

\section{Biomed Central}


negative environmental impact. Second, even though several varieties of coffee that are resistant to $H$. vastatrix have been used for introgression purposes $[3,4]$, such alternatives are time-consuming and do not provide durable resistance due to the rapid co-evolution of races of the fungus that harbor new virulence genes [5]. Therefore, additional methods to control leaf rust in the fields are required.

$H$. vastatrix is an obligate biotrophic parasite belonging to the division Basidiomycetes, order Pucciniales [6]. Following urediospore germination on the abaxial leaf surface, hyphae grow and penetrate intercellular spaces of the mesophyll tissue through stomatal openings before differentiating intra-cellular feeding structures, or haustoria. In susceptible coffee plants, the successful pathogen can complete its dikaryotic cycle within three weeks following infection and reach the ultimate stage, which is characterized by the formation of a sporulating sorus. In resistant plants, hyphal invasion is rapidly sensed and arrested within 2-3 days $[7,8]$. Based on quantitative and Mendelian genetic studies $[3,4]$, the occurrence of at least nine dominant resistance $(R)$ genes in Coffea spp., and a similar number of fungal virulence genes, have been inferred. It is thus commonly accepted that the outcome of coffee/rust interactions, whether the plant resists pathogen attack (incompatibility) or develops disease (compatibility), relies on the gene-for-gene model [9], which has been recently amended [10]. Once delivered into coffee cells, $H$. vastatrix effector proteins, and the intracellular perturbations that they trigger, are supposed to be perceived by specific $\mathrm{R}$-proteins. The recognition step promotes the launching of signaling defense pathway(s) and subsequent resistance. Alternatively, virulent rust races are believed to secrete effectors that escape or even counteract the host surveillance system, which allow for the highjacking of coffee cell metabolism and tissue colonization [11].

During incompatible interactions with biotrophic pathogens, the plant resistance phenotype results from the onset of a complex and multilayered-defense response, which is the so-called hypersensitive response or $\operatorname{HR}[12,13]$. Although little is still known about the molecular mechanisms that govern resistance to $H$. vastatrix, several studies have advanced the case for the existence of a HR-like phenomenon in coffee plants. Resistant varieties that were inoculated with avirulent fungal strains displayed a morphotype that exhibits many HR characteristics. These include rapid host cell death, which is localized at the infection site and that is associated with fungal hyphae collapse $[7,8]$, callose encasement of haustoria and subsequent cell wall lignification [8], early oxidative burst [14,15], and the activation of typical defense-related genes [16-18].

In previous work, we performed a suppression subtractive hybridization-based screening in C. arabica that had been challenged with $H$. vastatrix and identified a series of Expressed Sequence Tags (ESTs) that were regulated during compatible or incompatible interactions [16,19]. One of these ESTs shared a significant identity with the coding sequence of the NON-RACE-SPECIFIC DISEASE RESISTANCE 1 (NDR1) gene. Originally isolated in Arabidopsis thaliana, NDR1 encodes a small plasma membrane-resident protein, the deficiency of which was found to abolish HR and confer susceptibility to some fungal and bacterial pathogens carrying specific effector genes [20-22]. Notably, it has been established that NDR1-driven resistance is dependent on a specific subset of R-proteins (such as RPM1, RPS2 and RPS5) that are defined by the presence of a coiled-coil (CC) structure within their N-terminal parts [23]. From a mechanistic perspective, the best characterized example illustrating NDR1 function is the pathosystem involving strain DC3000::AvrRpt2 of the plant pathogenic bacterium Pseudomonas syringae pv. tomato (Pst). In this model, under resting conditions, AtNDR1 indirectly retains the RPS2 protein on the cytosolic side of the plasma membrane through its interaction with the RPM1-INTERACTING PROTEIN 4 (RIN4), thereby preventing HR activation [24]. Upon infection with Pst, the bacterial protease AvrRpt2 is secreted into the cytoplasm where it can cleave RIN4, releasing RPS2 and initiating a disease resistance signaling pathway [25].

In this study, we cloned two $C$. arabica candidate cDNAs for NDR1 and analyzed the deduced primary amino-acid sequences. Domain conservation and the high degree of homology between the coffee proteins and AtNDR1 led us to undertake a genetic complementation approach. Using the Arabidopsis ndr1-1 null mutant, we obtained genetic and molecular evidence that at least one of our candidate genes is a functional NDR1 ortholog. Both laser-confocal microscopy and biochemical analyses further suggested that the protein is likely to be attached to the plasma membrane via a glycosylphosphatidylinositol-anchor. Based on these data, the possibility that a NDR1-contingent mechanism could be invoked in $R$ gene-mediated resistance to $H$. vastatrix is discussed. The impact this result could have in the context of resistance improvement is also outlined.

\section{Results \\ Cloning and analysis of a novel NDR1 sequence homolog from Coffea arabica}

In previous work [19], we used a subtractive hybridization approach to identify genes involved in defense/resistance of coffee plants (C. arabica $L$.) to the orange rust fungus $H$. vastatrix. Of the 9 ESTs which were significantly up-regulated during HR, one displayed 43\% identity with the canonical NDR1 coding sequence from A. thaliana. In this study, we focused our efforts on the 
coffee candidate for NDR1 gene and isolated two distinct full-length transcripts by nested RACE-PCR. The corresponding cDNAs were cloned as described in the 'Methods' section (CaNDR1a [GenBank:DQ335596], CaNDR1b [GenBank:DQ335597]). Open reading frames differed from one another by only 3 single nucleotide positions with one of the substitutions being non-silent (F69L). Both sequences were predicted to encode proteins that were 214 amino acids long, which shared a calculated molecular weight of $23.8 \mathrm{kDa}$ and an isoelectric point of 9.58 .

Searching for Arabidopsis relatives of our proteins, we screened the GenBank database by means of the BLAST P algorithm [26] and retrieved 15 non-redundant hits. As expected, the best match appeared to be NDR1 with 42/61\% identity/homology. Apart from an unknown sequence, all identified homologs had been previously described as members of the NDR1/HIN1-like (NHL) protein superfamily [27]. NHLs account for a vast class of plant defense-associated proteins that, within their $\mathrm{N}$ terminal halves, contain two highly conserved peptide patterns (motifs 2 and 3 ) and a less conserved one (motif 1 ) [28]. Alignment of the proteins, along with the tobacco HIN1 for comparison, revealed the position of the three motifs within sequences (Figure 1; see also additional file 1 for full length sequence alignment). A phylogenetic analysis using solely the conserved region that is presented in Figure 1, and which encompasses the three NHL motifs, showed that CaNDR1a/b, NDR1, NHL38 and NHL16 formed a group that was distinct from other NHLs (Figure 2a,b). These data indicate that NDR1, NHL38 and NHL16 are the closest Arabidopsis relatives of CaNDR1a/b.

\section{Ectopic expression of CaNDR1a in Arabidopsis ndr1-1 null mutant restores specific resistance to Pseudomonas syringae pv. tomato (DC3000::AvrRpt2)}

From our in silico analysis, the question arises as to whether the two identified coffee genes are functional homologs of AtNDR1 or code for distinct NHL counterparts. To answer this question, a genetic complementation approach was undertaken. Given the high degree of identity between the two predicted CaNDR1 amino-acid sequences, we decided to study CaNDR1a and expressed the corresponding ORF under the control of the CaMV35S promoter in the Arabidopsis $n d r 1-1$ null mutant. Segregation analysis on a selective medium allowed for the isolation of single-locus, homozygous insertion lines (see additional file 2 for segregation results). T3 lines were then screened by RT-qPCR for high steady-state levels of transgene transcripts and three of them were selected for further experiments. The expression level of CaNDR1a in these lines, designated T3-1, T3-2 and T3-3, was respectively 92-, 190-, and 714-fold higher than that of the endogenous AtNDR1 gene, when compared to WT Col-O plants grown under the exact same conditions.

Previous work has shown that the $n d r 1-1$ null mutant is incapable of HR activation in response to Pst strain

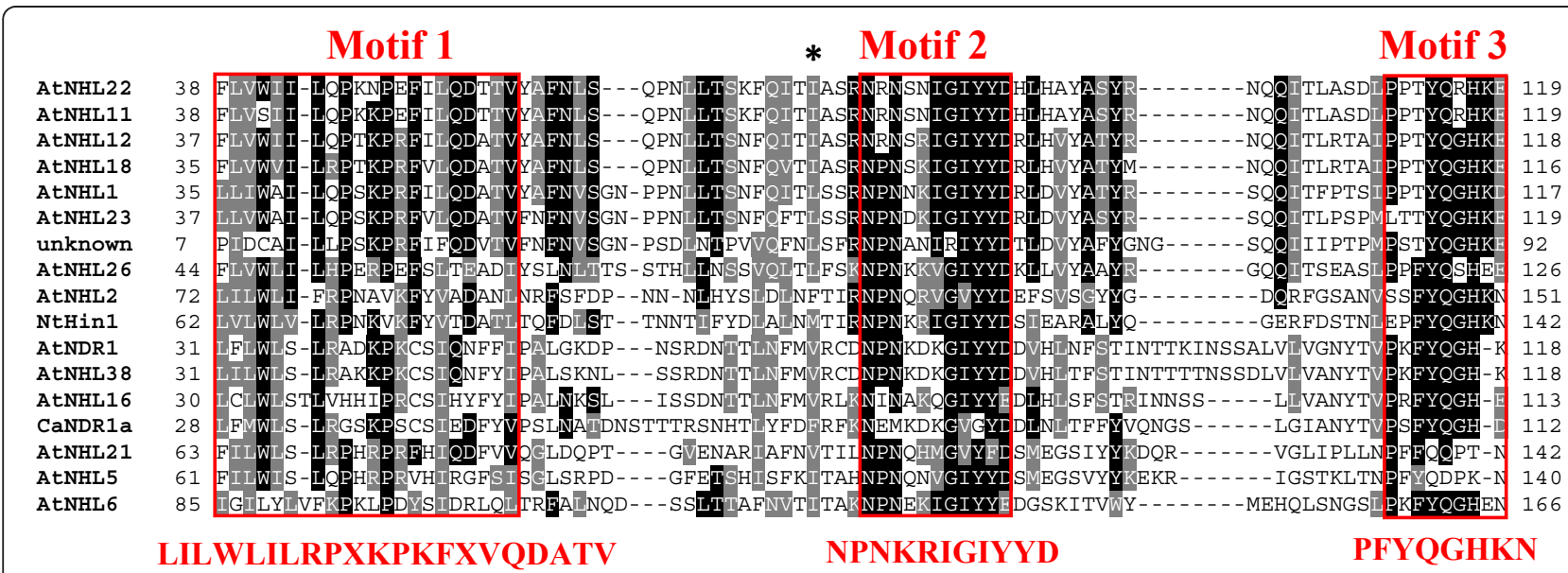

Figure 1 The two coffee candidates for NDR1 protein belong to the NHL family. Putative Arabidopsis orthologs of CaNDR1a/b proteins were identified by means of the BLAST algorithm using as queries the two deduced coffee amino-acid sequences. The retrieved sequences were aligned using version 2.0.10 of the Clustal X program [59] and the resulting alignment was then processed online at the BoxShade server (http://www.ch.embnet.org/software/BOX_form.html). The conserved region containing the three NHL motifs is presented. The position of the motifs is indicated with red lines and numbers. An asterik shows the position of the substituted amino-acid residue between the two coffee proteins (F69L). The full length sequence alignment can be found in Additional file 1. Accession numbers of the genes coding for the Arabidopsis proteins are as follows: NDR1 [AGl:At3g20600]; NHL1 [AGl:At3g11660]; NHL2 [AGl:At3g11650]; NHL5 [AGl:At1g61760]; NHL6, [AGl: At1g65690]; NHL11 [AGl:At2g35970]; NHL12 [AGl:At2g35960; NHL16 [AGl:At3g20610]; NHL18 [AGl:At3g52470]; NHL21 [AGl:At4g05220]; NHL22 [AGl: At4g09590]; NHL23 [AGl:At5g06330]; NHL26 [AGl:At5g53730]; NHL38 [AGl:At3g20590]; unknown, [AGl:At5g05657]. The accession number of the Nicotiana tabacum Hin1 coding sequence is GenBank: AB091429.1. 

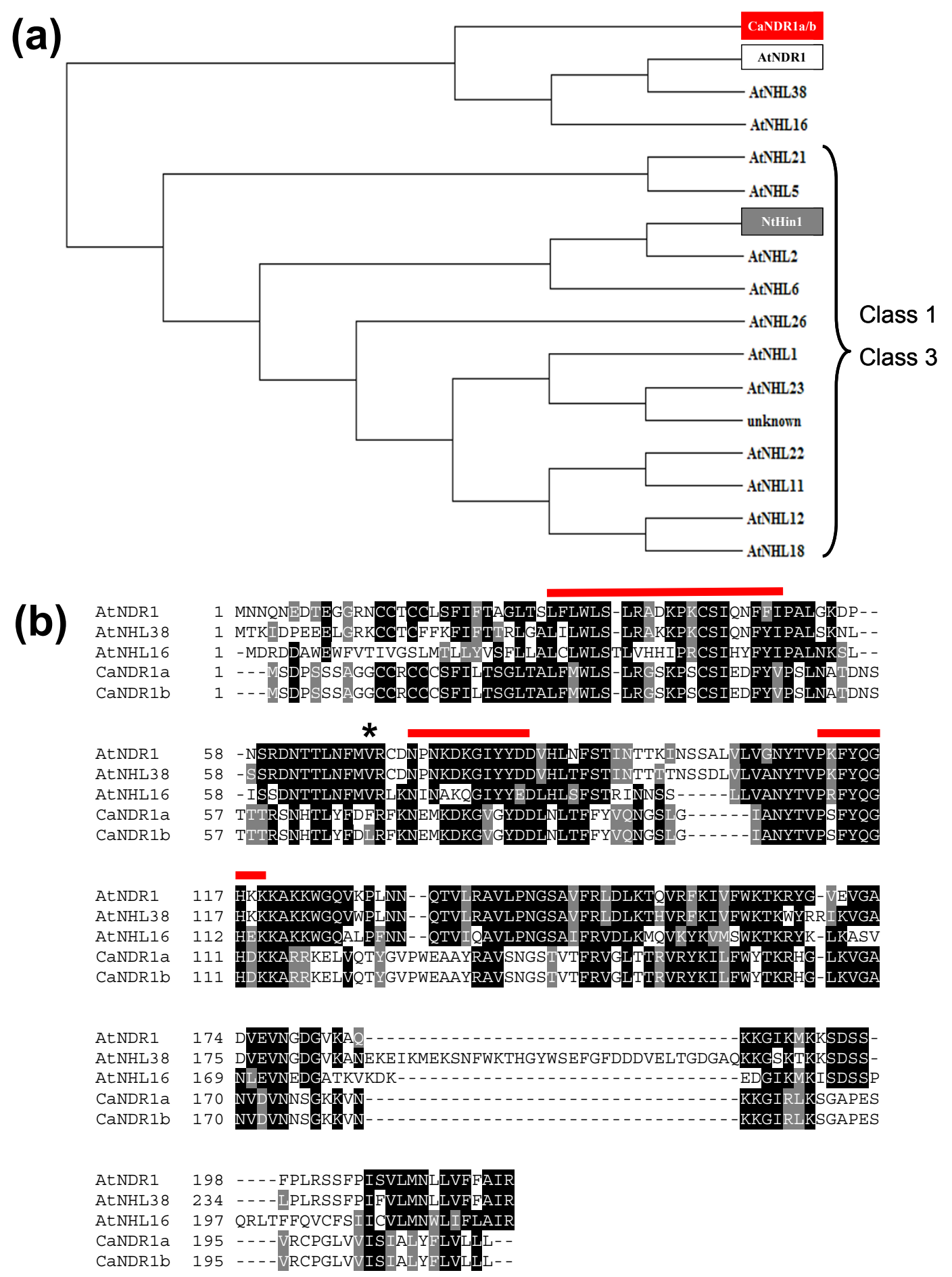

Figure 2 NDR1, NHL16 and NHL38 are the closest Arabidopsis relatives of CaNDR1 proteins. (a) Phylogenetic relationships between CaNDR1 proteins and their Arabidopsis relatives. The phylogenetic tree was built using the Phylowin freeware using the neighbor-joining method [60]. Sequence alignment was previously obtained using version 2.0 .10 of the Clustal X program [59]. (b) Full length sequence alignment of CaNDR1a/b and the Arabidopsis protein NDR1, NHL16 and NHL38. Locations of the three NHL motifs within sequences are indicated with red lines above the alignment. The star indicates the amino acid residue substituted between both coffee NDR1 sequences. For sequence accession numbers, see legend of Figure 1. 
DC3000::AvrRpt2 carrying an AvrRpt2 cassette-containing plasmid $[20,21]$. Conversely, a high overexpression level of $A t N D R 1$ in the Col-O genetic background was found to confer enhanced disease resistance to strain DC3000 [22]. The behavior of our overexpressor lines was thus examined in response to the two isogenic bacterial strains (DC3000::AvrRpt2 and DC3000) by recording macroscopic symptoms and following in planta bacterial growth over a four-day period. Although Coppinger et al. [22] had previously reported the occurrence of HR-like lesions in non-inoculated Arabidopsis transgenic lines overexpressing AtNDR1, no such lesions were observed in our non-inoculated T3 lines. Although the three genotypes developed disease symptoms in response to DC3000 (Figure 3a), T3-2 and T3-3 lines were less susceptible than the $n d r 1-1$ mutant plants, as shown by the leaf bacterial contents at four days postinoculation (dpi) (Figure 3c). Upon a challenge with DC3000::AvrRpt2, WT plants exhibited typical hypersensitive lesions located within the infiltrated area, whereas ndr1-1 mutants showed disease-like symptoms characterized by tissue yellowing, which spread outside the inoculated zone (Figure 3a). As expected, such striking differences between the WT and $n d r 1-1$ genotypes were closely correlated with leaf bacterial amounts. For instance, as early as $2 \mathrm{dpi}$, mutant leaves already showed a 10-fold increase in the concentration of bacteria compared to WT leaves (Figure 3b). More importantly, when inoculated with strain DC3000::AvrRpt2, all three CaNDR1a-expressing lines presented a HR-like phenotype (Figure 3a) that was associated with bacterial levels statistically comparable to that of WT plants (Figure 3b). Furthermore, expression of the coffee transgene in the Arabidopsis mutant had no significant impact on the RPS4-coordinated HR that had been previously shown to be independent of AtNDR1 [23] (Additional file 3). Altogether, these results provide genetic evidence that CaNDR1a functionally and specifically complements the ndr1-1 mutant.

\section{The mature CaNDR1a protein is C-terminally processed}

The Arabidopsis NDR1 protein undergoes several posttranslational modifications, including multiple glycosylations and $\mathrm{C}$-terminus processing. The latter cleavage removes a small portion of the protein, thereby freeing an amino-acid residue known as a $\omega$-site (Figure 4) that was proposed to be modified by covalent binding to a glycosylphosphatidyl-inositol (GPI)-anchor [22]. In accordance with the cognate role of AtNDR1 in disease resistance signalling [23], GPI anchoring is usually encountered in eukaryotic plasma membrane-resident proteins and allows for the cell surface-tethering phenomenon [29]. Although there is no established consensus sequence of GPI-anchor attachment sites, prediction algorithms are available online. Using the Big-Pi Plant Predictor [30,31], we identified two putative overlapping cleavage sites in the primary amino-acid sequence of CaNDR1a (Figure 4), with residues S189 and G190 being strong $\omega$-site candidates (with $P$-values of $2.48 \times 10^{-6}$ and $2.76 \times 10^{-5}$, respectively). Furthermore, CaNDR1a and its Arabidopsis ortholog share common structural features that are believed to be necessary for GPI attachment by the transamidase complex in endoplasmic reticulum (ER) membranes [31]. Directly downstream of the potential $\omega$-residues is a region predicted to encompass a short polar spacer, followed by a hydrophobic tail. An uncleavable signal peptide (1-39) comprising a potential transmembrane domain (1632) was also predicted with a high probability of occurrence $(P=0.867)$ using SignalP-3.0 software [32,33]. As previously suggested [22], this $\mathrm{N}$-terminal signal sequence might be required for the protein to enter the ER network and travel through the secretory pathway.

Based on this in silico analysis, we decided to investigate the possibility of $\mathrm{C}$-terminus processing for CaNDR1a. To this end, a doubly-tagged CaNDR1a version (HA-CaNDR1a-His) was created (Figure 5a) and transiently expressed in tobacco leaves. We reasoned that, if the CaNDR1a protein is cleaved in tobacco cells, the loss of its Cterminus should be easily visualized upon immunoblotting by the absence of a His-specific signal, whereas the proof that the protein is synthesized would be provided by the presence of a HA-specific signal.

Two to three days post-infiltration with an Agrobacterium strain, which was dedicated to the expression of the HA-CaNDR1a-His construct, protein extracts prepared from fresh tissues were resolved by SDS-PAGE and immunoblotted using either HA- or His-specific antisera as described in the 'Methods' section. Immunoblot conditions were tested using a N-terminally HA-tagged CaNDR1a (HA-CaNDR1; Figure 5a) and C-terminally His-tagged Bax Inhibitor 1 (BI1-His) versions as controls. Six independent experiments including independent Agrobacterium infiltrations and protein extractions were carried out. Using anti-HA antibody, only one major band was detectable in lanes loaded with NDR1 samples (Figure 5b, lanes 3-6), whereas no specific signal was visualized in lanes loaded with negative control samples (Figure 5b, lanes 1, 2 \& 7). Although the nucleotide sequences of $H A-C a N D R 1 a$ and HA-CaNDR1a-His code for proteins with predicted molecular weights averaging $25-26 \mathrm{kDa}$, the detected proteins migrated to approximately $45 \mathrm{kDa}$ under denaturating conditions. Such an apparent discrepancy is not surprising based on previous work. Coppinger and coworkers [22], indeed, showed that the native AtNDR1 protein resolved by SDS-PAGE displays a mass of about $48 \mathrm{kDa}$ instead of the predicted $24.6 \mathrm{kDa}$. These authors further demonstrated that the protein regains its theoretical size when translated in vitro without the machinery dedicated 


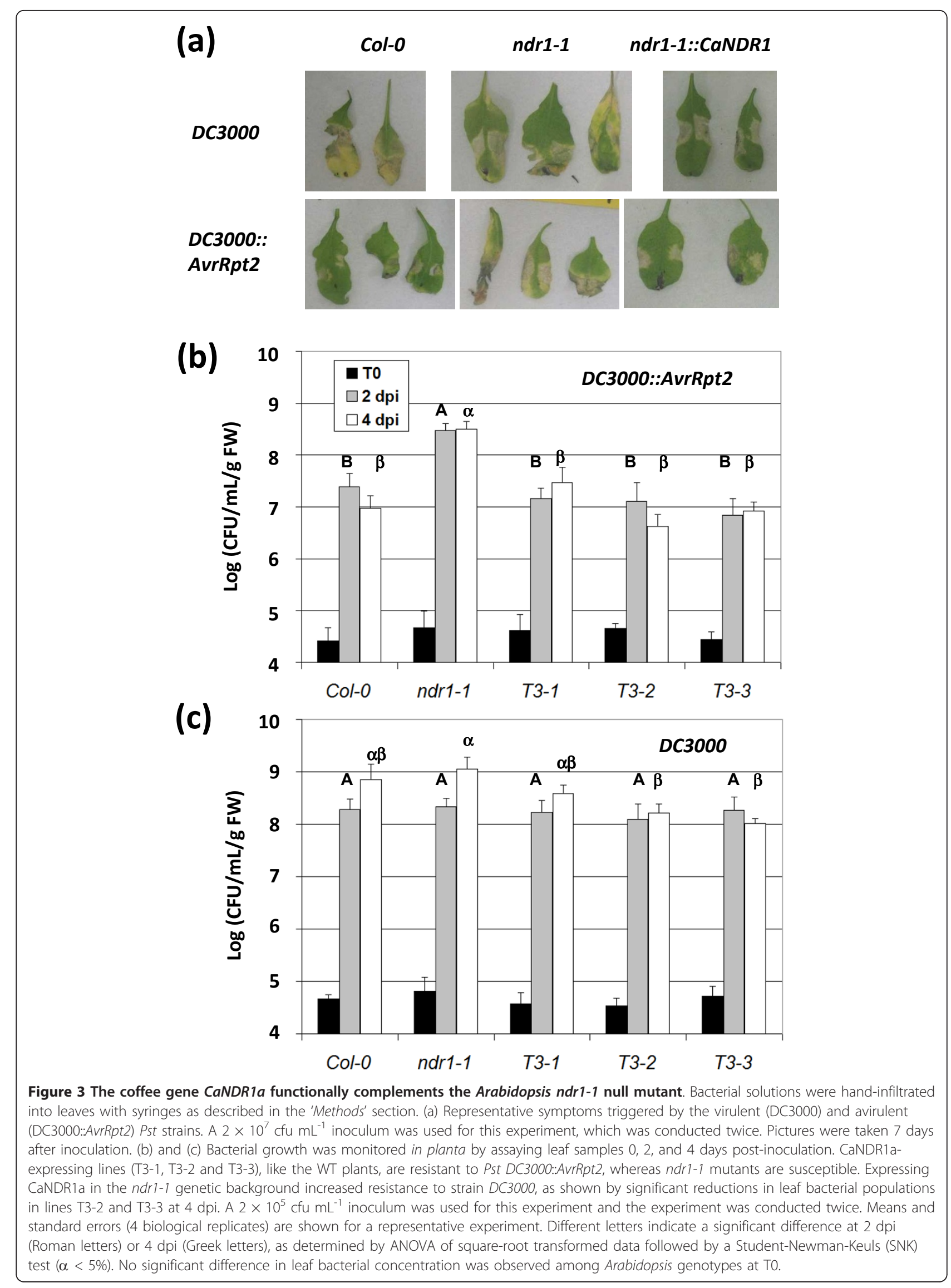




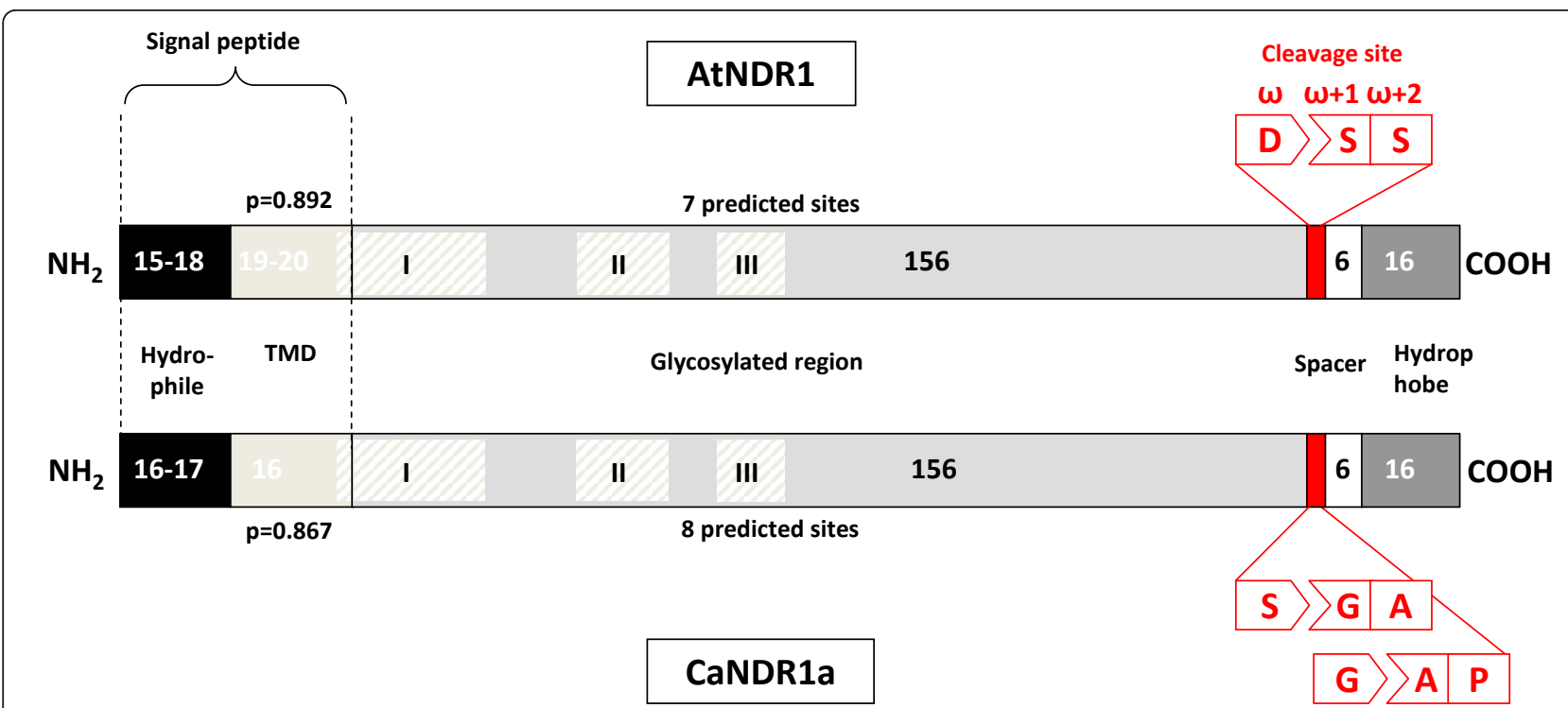

Figure 4 Structural similarities between the Arabidopsis and coffee NDR1 proteins. Predicted structural domains and motifs of NDR1 proteins are represented. The overall structure of both proteins appears conserved; it is furthermore reminiscent of GPI-anchored proteins [29]. The C-terminus of NDR1 proteins exhibits putative cleavage sites, including the $\omega$-site to which the glycolipid moiety of the anchor is attached. Domains following the attachment site display the necessary features for proper transamidase activity, the enzyme complex involved in GPI modifications of proteins and localized to the ER membrane. A putative uncleavable N-terminal signal peptide that might be implicated in ER targetting is also present in both proteins. TMD indicates a predicted transmembrane domain. The size of each protein domain is indicated as Arabic numbers. The number of predicted glycosylation sites (in the middle domain, shown in light grey) is also indicated above and below the proteins. For convenience, the three conserved NHL motifs are shown as hatched regions I, II and III. Predictive models and methods used for building this scheme are described in the 'Methods' section.

to glycosylation, indicating that the latter post-translational modification could account for the migration shift of the mature proteins on polyacrylamide gels. Consistently, the CaNDR1a protein, like its Arabidopsis ortholog, exhibits a significant number of putative glycosylation sites (Figure 4). Hence, one can assume that our protein extracts (Figure 5b, lanes 3-6) are likely to contain glycosylated forms of CaNDR1a, the migration behavior of which is altered on polyacrylamide gels.

Finally, using the same set of samples and anti-His antibody, we were unable to detect HA-NDR1-His protein (Figure 5b, lanes 4-6), whereas BI1-His protein (31 kDa) was clearly identified (Figure $5 \mathrm{~b}$, lane 7 ). The latter data indicate that CaNDR1a is C-terminally processed in tobacco leaves, which strongly suggests that the protein is modified by addition of a GPI moiety. Further experiments are nevertheless needed to confirm this assumption.

\section{CaNDR1a is localized to the plasma membrane}

Indirect data support the association of the CaNDR1a protein with membranes: (i) the potential post-translational modification by addition of a GPI-anchor; (ii) a predicted transmembrane-spanning domain located within the $\mathrm{N}$-terminal signal peptide (Figure 4), and (iii) the need of a detergent for the protein to be extracted from tobacco leaf tissues when transiently expressed
(Additional file 4). Accordingly, the CaNDR1a protein was predicted to be localized to the plasma membrane (PM) using ChloroP1.1 and PSORTII software [34,35]. Therefore, in order to assess its subcellular localization, a GFP6 translational fusion was created (Figure 6a), transformed into leaf epidermal tobacco cells using Agrobacterium tumefaciens as the vector, and imaged by confocal microscopy (as described in the 'Methods' section). In accordance with our working hypothesis, independent experiments showed a consistent fluorescent pattern delineating cellular contours (Figure 6b, panel i). Such a pattern was also observed (Figure 6b, panel ii) with a PMresident protein fused to mCherry fluorophore [36]. In addition, further experiments where both proteins were simultaneously expressed in the same cells revealed a significant overlap between the GFP6 and mCherry signals at the cell surface (Figure $6 \mathrm{~b}$, panels iv, v, vi). It is noteworthy that a few GFP6-CaNDR1a-expressing cells displayed not only cell surface labeling, but also internal fluorescence resembling an ER-like reticulated network with brighter dots that could represent Golgi structures (Figure 6b, panel iii).

Because leaf epidermal tobacco cells possess a large central vacuole that presses the cytoplasmic compartment against the PM and cell wall, it is difficult to conclude on the subcellular localization of CaNDR1a based solely on 


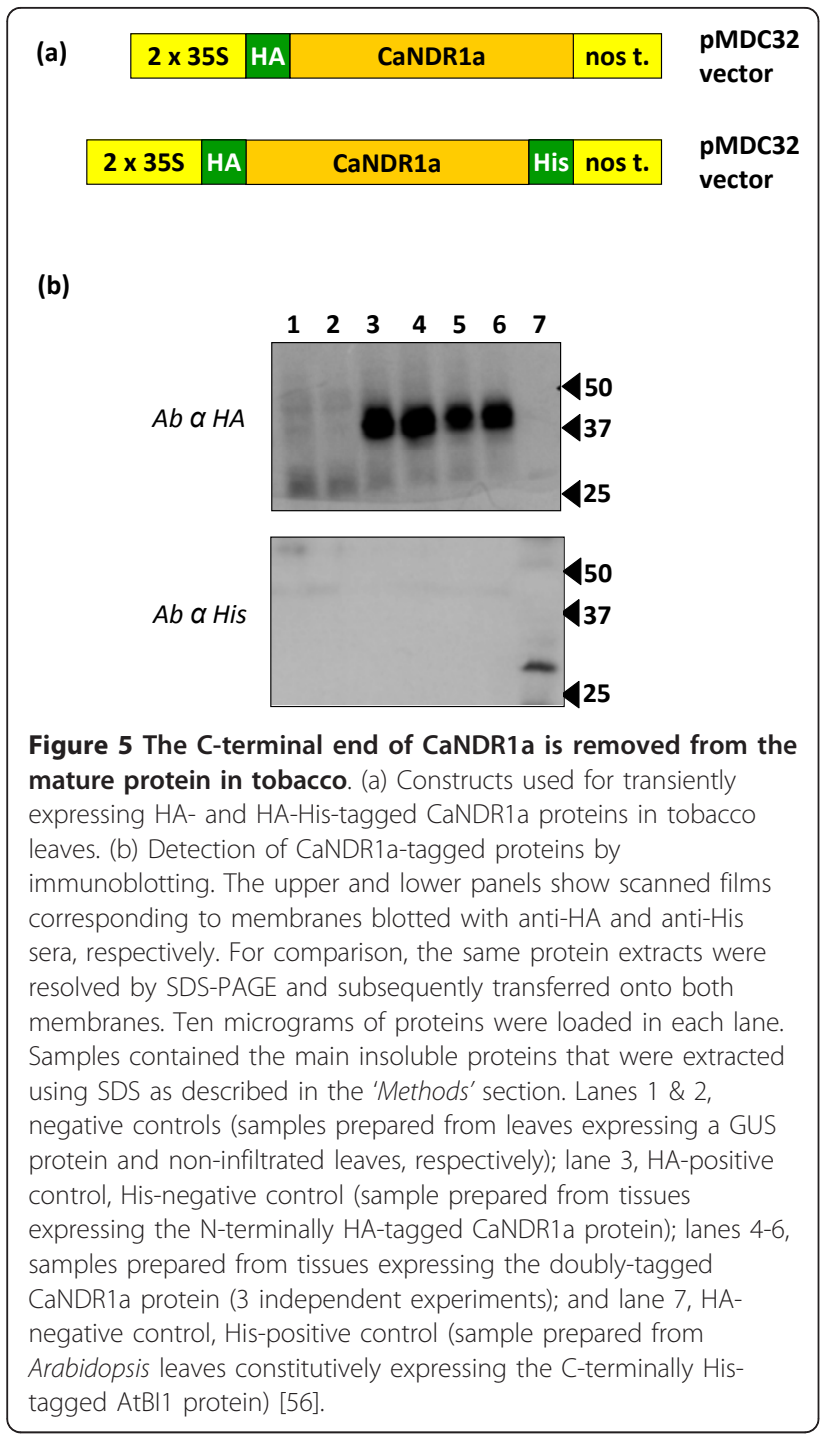

our microscopy data. In order to unambigously ascertain the localization of CaNDR1a, the N-terminally HAtagged version of CaNDR1a (Figure 5a) was transiently expressed in tobacco leaves and purified PM fractions were directly tested for the presence of the protein by immunoblotting using HA-specific antisera. Immunoblotting of crude extracts (CE) prepared by directly boiling agroinfiltrated tissues in Laemmli buffer indicated that HA-CaNDR1a proteins were succesfully expressed in plant cells (Figure 7a). Most importantly, the tagged version of CaNDR1a was significantly enriched in PM fractions compared to microsomal ones, as also observed for the endogenous PM-resident protein PMA2 (Figure $7 b)$. In addition, while no signal was detected when 5, 10 and $15 \mu \mathrm{g}$ proteins of the soluble fraction $(100.000 \times \mathrm{g}$ supernatant) was blotted, a HA-specific band, the intensity of which increased with the amount of total proteins loaded, was clearly visualized (Figure 7c). Altogether, these results show that the mature CaNDR1a protein is targeted to PM in the tobacco heterologous system, further suggesting a similar subcellular localization for the protein in coffee cells.

\section{Identification of a potential homologous RIN4 protein from coffee plants}

The Arabidopsis NDR1 protein has been demonstrated to physically interact with RIN4 both in a yeast heterologous system and in planta [24]. Searching for RIN4 sequence homologs in the HarvEST ${ }^{\odot}$ Coffea database resulted in the identification of a candidate contig from Coffea canephora [GenBank: DV705409.1]. The deduced protein sequence shares a high percentage of identity/ homology (36/53\%) with the beginning of our query sequence, AtRIN4. This region is also highly conserved within the RIN4 family of proteins (Figure 8a). One of the two cleavage sites that permit the hydrolysis of RIN4 upon delivery of the bacterial protease AvrRpt2 into Arabidopsis cells $[25,37,38]$ is also conserved in the coffee protein (Figure 8a). In line with our previous data (Figures 5, 6 and 7), this in silico analysis points to potential mechanistic conservation of the NDR1 function in Arabidopsis and coffee plants.

\section{Discussion}

The Arabidopsis $n d r 1$ locus was identified in the late 1990 's using a forward genetic screen based on the loss of resistance to the Pst strain DC3000::AvrRpt2 [20,21]. Since then, NDR1 homologous genes have been found by sequence comparison in other plant species such as Brassica napus [39] and Vitis vinifera [40]. Many sequence homologs (around 19 non-redundant hits within 11 plant species) can also be retrieved from the GenBank database by means of the BLAST P algorithm (data not shown). However, to our knowledge, our data constitute a novel report on the identification and characterization of a functional NDR1 homolog, despite the plethora of orthologous candidates.

In this study, several lines of evidence indeed demonstrated that ectopic expression of CaNDR1a coding sequence was able to rescue the phenotype of the Arabidopsis ndr1-1 null mutant. Upon infection with DC3000:: AvrRpt2, the three mutant lines expressing the coffee transgene were found to develop hypersensitive cell death symptoms that were absent in mutant plants (Figure 3a). This macroscopic study was further corroborated by two independent in planta bacterial growth assays showing that leaf populations of the bacterial pathogen in our transgenic lines were low and comparable to those of WT plants (Figure 3b). In addition, high overexpression level of the coffee CaNDR1a gene in the Col-O genetic background was also found to confer enhanced disease resistance to the DC3000 strain, as previously reported 


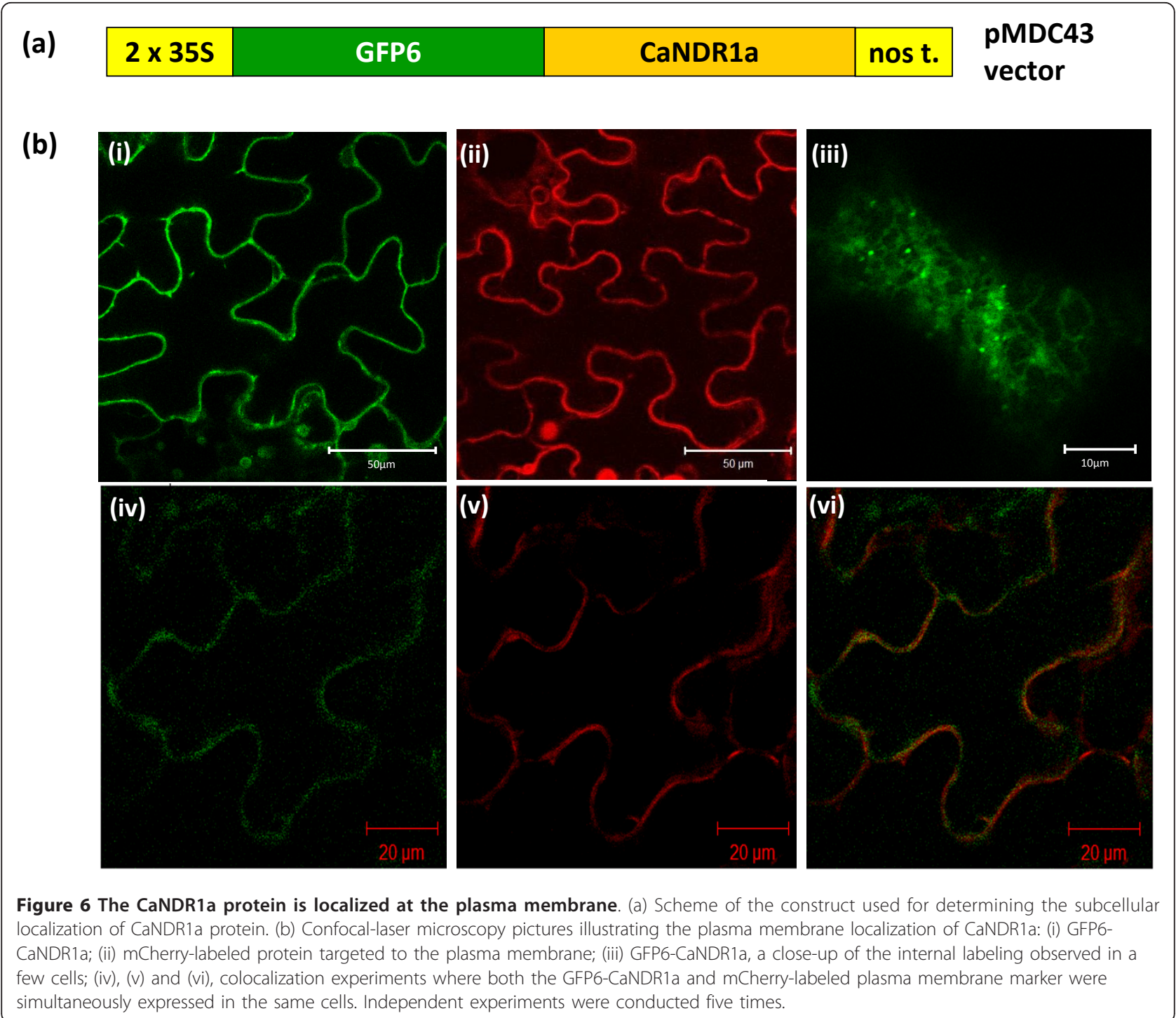

when the AtNDR1 gene was overexpressed in A. thaliana [22].

Importantly, NDR1-driven resistance in A. thaliana is not restricted to bacterial pathogen attacks. Two reports have demonstrated that the $n d r 1$ mutation renders plants susceptible to infection by the oomycete Hyaloperonospora arabidopsidis [20] and the fungus Verticillium longisporum [41]. Therefore, given that (i) CaNDR1a is a functional homolog of the Arabidopsis NDR1 gene, and (ii) transcripts of the former accumulate in coffee leaves undergoing $\mathrm{HR}$ in response to the fungus $H$. vastatrix $[16,19]$, it would not be surprising if NDR1 proteins could regulate the defense signaling pathway(s) leading to coffee rust resistance. This hypothesis is currently under investigation in our laboratory using a functional approach. Recently, we also showed that $A$. thaliana Col-O plants display a rapid non-host response to $H$. vastatrix. This response is reminiscent of HR in that it prevents haustorium formation and hyphal spread in plant tissues [42]. This work raises the possibility of testing the role of NDR1 in response to the coffee leaf rust in the A. thaliana heterologous system.

As predicted by our bioinformatic analysis, imaging of GFP6-tagged CaNDR1a protein by confocal microscopy revealed a fluorescent pattern that was consistent with a plasma membrane localization (Figure 6b, (i)). Colocalization experiments with a PM fluorescent protein marker also supported this observation (Figure 6b, (iv-vi)). Furthermore, the need of an anionic detergent like sodium dodecyl-sulfate for the HA-tagged CaNDR1a proteins to be extracted from tobacco leaves (Additional file 4) indicated an association with membranes. Finally, our biochemical approach based on the purification of PM by two-phase PEG/dextran partitioning (Figure 7b,c) 


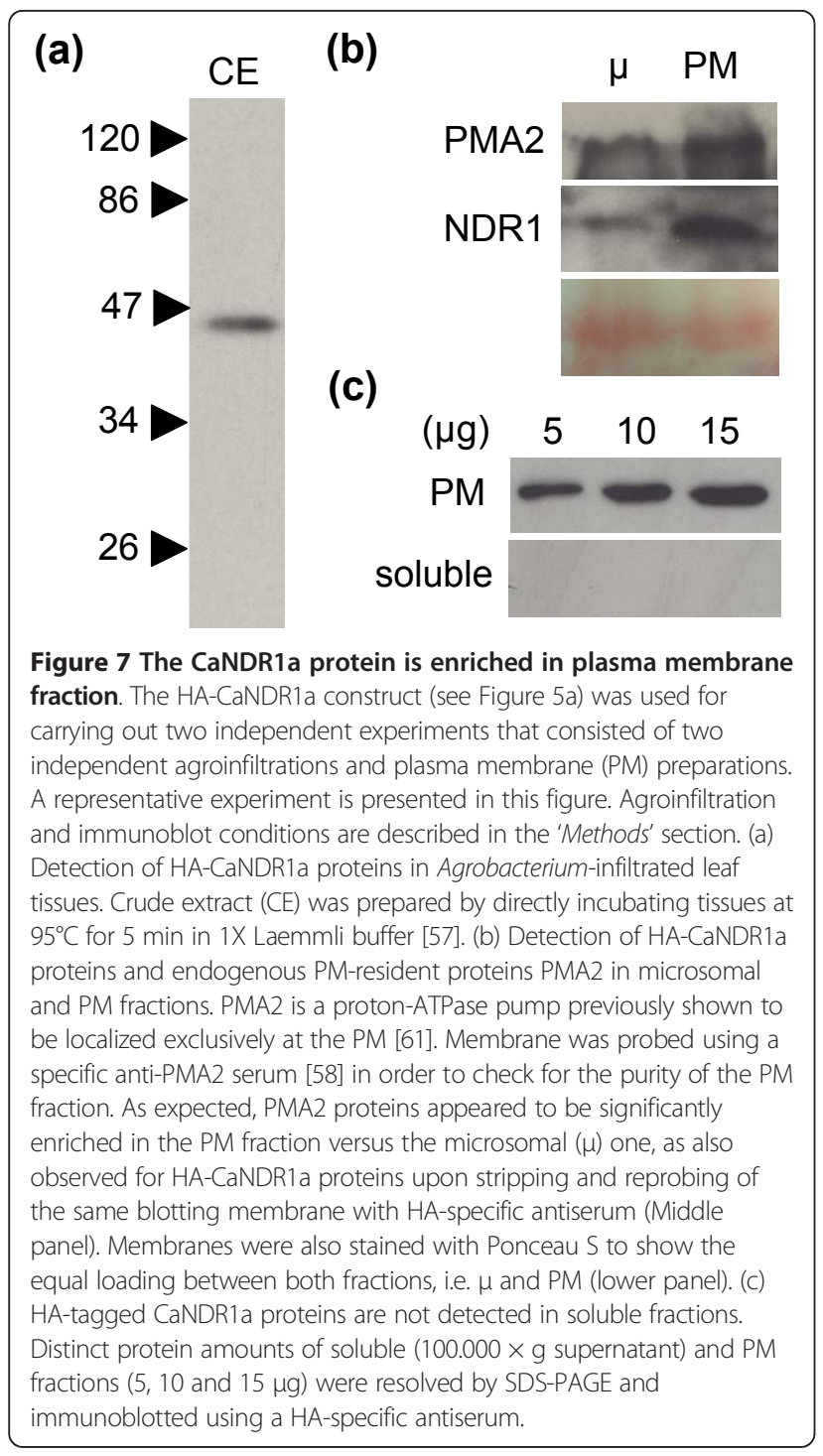

clearly demonstrated the presence of HA-CaNDR1a proteins in tobacco PM fractions. Therefore, it is likely that the mature CaNDR1a protein resides in the plasma membrane of coffee cells.

No fluorescent labeling of the organelle corresponding to a GFP6 spectrum was observed in chloroplasts, although it had been reported previously for a tagged version of AtNDR1 [27]. Instead, internal reticulated labeling reminiscent of the ER network (Figure 6b, (iii)) was observed in a few cases and may correspond to cells overloaded with the ectopic fluorescent proteins. This observation is consistent with our results, suggesting that the CaNDR1a protein could be modified by addition of a GPI moiety to its C-terminal part (Figure $5 b)$. It has been well-described that proteins tethered to the cell surface by means of a GPI anchor undergo this sort of post-translational modification in the ER before being sorted via the secretory pathway to their final destination, i.e., the plasma membrane.

Usually, GPI-anchored-proteins are also thought to locate on the apoplasm side of the plasma membrane [43]. In A. thaliana, it has been clearly established that NDR1 is attached to the plasma membrane through a C-terminal GPI anchor [22]. It has also been inferred that the N-terminal portion of NDR1 lies within the cytoplasm because it was found to interact with the cytosolic protein RIN4 in planta [24]. Since the C-terminal anchor of AtNDR1 is resistant to cleavage by phospholipase $C$, these data further led to the hypothesis that the protein possesses a transmembrane-spanning domain as a second anchor site. This was recently corroborated by a modelling study [44] and, in fact, the coffee protein, like its Arabidopsis relative, was predicted to present a single transmembrane domain (Figure 4), suggesting a similar, but atypical topology of the two counterparts (Figure $8 b$ ).

Recently, a new mode of action of NDR1 was revealed by Knepper et al. [44]. Based on structural homology with mammalian integrins and the Arabidopsis late embryogenesis abundant (LEA) protein 14, known to be involved in abiotic stress response [45], the aforementioned authors investigated the possibility that AtNDR1 may control cell integrity through PM-cell wall adhesions. Besides its wellcharacterized role as a key signaling component during pathogen attack, a broader function for NDR1 is strongly suggested by the data in mediating primary cellular functions in Arabidospsis through maintenance of PM-cell wall connections [44]. From these unexpected results, the question arises as to whether or not CaNDR1a could perform a similar function in C. arabica.

Interestingly, upon inoculation with DC3000::AvrRpt2, successful activation of HR required NDR1-RIN4 physical interaction. Further examination using an alanine-scanning mutagenesis strategy revealed that two amino acid residues within the $\mathrm{N}$-terminal part of NDR1 were necessary for the interaction [24]. Despite the apparent lack of conservation of these two amino acid determinants within the CaNDR1a end (Figure 8c), our results showing that the coffee gene was able to restore RPS2-mediated resistance in the $n d r 1-1$ mutant tend to prove that CaNDR1a does interact with AtRIN4 in our transgenic lines. Thus, this raises the possibility that mechanism(s) whereby NDR1 proteins exert their function could be conserved in Arabidopsis and coffee plants.

Consistent with this idea, searching for RIN4 sequence homologs in the HarvEST ${ }^{\odot}$ Coffea database resulted in the identification of a candidate contig from Coffea canephora. The deduced protein shows, within its N-terminal portion, a highly conserved region with the members of the RIN4 family, as well as a putative conserved canonical AvrRpt2 cleavage site (Figure 8a). Nonetheless, further experiments are needed to answer the question as to 


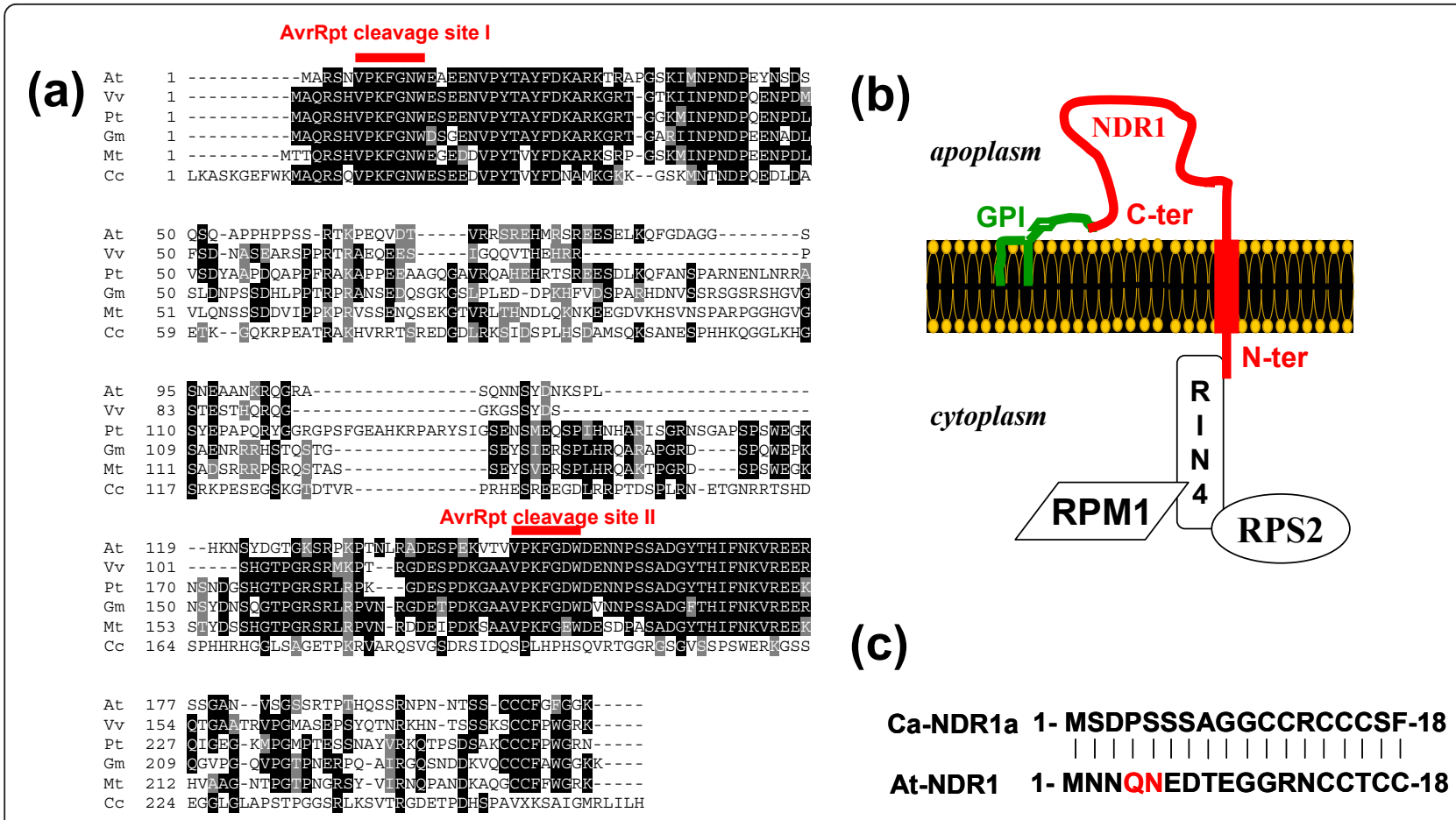

Figure 8 Putative mechanistic conservation of NDR1 function. (a) Alignment of RIN4 homologous sequences. The closest sequence homologs of AtRIN4 [AGl:At3g25070] were aligned with the putative coffee RIN4 protein [harvEST:Coffea:UG5351] using ClustalX [59]. The positions of the two AvrRpt2 cleavage sites [37,38] are highlighted in red. Accession numbers of the genes coding for the proteins presented in the figure are as follows: Glycine max Gm [GenBank:ADJ67468]; Medicago truncatula Mt [GenBank:ACJ83941]; Populus trichocarpa Pt [GenBank: XP_002301798]; Vitis vinifera, Vv [GenBank:CBI33050]. (b) Scheme showing how NDR1 is anchored to the plasma membrane. AtNDR1 indirectly retains both R-proteins, RPS2 and RPM1, at the plasma membrane via its interaction with RIN4 [24,48]. (c) Comparison of the N-terminal portions of the two orthologous NDR1 proteins from A. thaliana and C. arabica. Amino-acid residues necessary for the interaction with AtRIN4 are highlighted in red. Intriguingly, these residues do not seem to be conserved in the coffee sequence.

whether or not CaNDR1a, like its Arabidopsis ortholog, could serve as a PM anchor that indirectly recruits Rprotein(s) via its interaction with RIN4-like intermediates (Figure $8 \mathrm{~b}$ ) $[24,46]$. Split-ubiquitin and yeast two-hybrid systems, combined with bimolecular fluorescence complementation (BiFC), would be useful tools for tackling this question. This might also be a faster and more convenient strategy, as opposed to classical genetic approaches, for the isolation of $R$-gene(s) conferring resistance to $H$. vastatrix. To date, no coffee $R$-gene(s) have been isolated despite the efforts of the coffee research community $[3,4]$. The reproductive barriers affecting genetic exchanges between diploid coffee species and the allopolyploid C. arabica have thus far prevented the successful isolation of the loci responsible for resistance to $H$. vastatrix through a map-based cloning strategy [4].

\section{Conclusions}

The functional and biochemical characterization of the orthologous NDR1 protein from C. arabica that we have carried out represents a crucial step towards the elucidation of the molecular events underpinning resistance to coffee rust. It should help identify new players in the coffee NDR1-dependent signaling pathway(s) in the near future, and might thus be crucial for the engineering of transgenic coffee plants with broad spectrum resistance to $H$. vastatrix races. The development of efficient techniques to transform and propagate coffee varieties renders these biotechnological approaches feasible $[47,48]$.

\section{Methods}

\section{Plants and growth conditions}

Tobacco plants (Nicotiana benthamiana) that were used for transient expression experiments were grown in a greenhouse, at $150 \mu \mathrm{mol} / \mathrm{m}^{2} / \mathrm{s}$ light radiance, with a $14 /$ $10 \mathrm{~h}, 23 / 20^{\circ} \mathrm{C}$ light-dark cycle, and $60 \%$ relative humidity.

Wild-type Arabidopsis thaliana ecotype Columbia (Col-0), ndr1-1 null mutants [20], and transgenic lines expressing CaNDR1a were all grown in a growth chamber under short-day conditions $(10 \mathrm{~h}$ photoperiod, $100 \mu \mathrm{mol} / \mathrm{m}^{2} / \mathrm{s}$ light fluency), at $22 / 20^{\circ} \mathrm{C}$ day/night with 
$80 \%$ relative humidity. Pathogen challenge conditions are described hereafter.

\section{Isolation and cloning of CaNDR1a/b cDNA}

As previously described [19], the 5' end of the CaNDR1 cDNA that is referred to as DSS12 had already been sequenced (Genbank:CO773976). 3'-RACE PCR was thus conducted to determine the sequence of the full-length cDNA. Total RNA $(1 \mu \mathrm{g})$ isolated from C. arabica cv. caturra leaves that had been challenged with $H$. vastatrix for 18 hours were first reverse-transcribed using the Smart CDS primer and a combination of the Omniscript RT (Qiagen, Courtaboeuf, France) and SMART PCR cDNA synthesis kits (Clontech, Mountain View, CA, USA). RACE assays were then performed using specific oligonucleotides designed in the 5 ' non-coding region (3R-NDR1, 5'-CTACTTTGTTCACTGGTAGTCCCTC-3'; n3R-N DR1, 5'-CATAATACTTCACCGGAGAACCACC-3') and the 5'PCR Smart primer (Clontech). The resulting 1-kb PCR product was cloned into the pGEM-Teasy vector (Promega, Charbonnières-les-bains, France) and finally sequenced (Genome Express, Grenoble, France).

\section{Constructs}

To assess the complementation of the Arabidopsis null mutant $n d r 1-1$ [20], the open reading frame of CaNDR1a was cloned into the binary vector pCAMBIA 1305.1 (Cambia, Brisbane, Australia) downstream of the strong and constitutive $35 \mathrm{~S}$ promoter of the cauliflower mosaic virus. For this purpose, the iud gene was removed from the vector by restriction digestion with BgIII and BstEII enzymes. The coding sequence of CaNDR1a was amplified by PCR (DAP Goldstar DNA polymerase, Eurogentec, Seraing, Belgium) using the corresponding pGEM-T clone (GenBank:DQ335596) as a template and the following primers: CaNDR1-BglII 5'-TCAGATCTTATGGACAAAGGATGGGGC-3', and CaNDR1-BstEII 5'-TAGGTCAC CAAATTAATTCCCAGGAAA-3'. Digested PCR products were then ligated into the binary vector to get the final construct.

To test the hypothesis that the C-terminal part of CaNDR1a is removed from the mature protein, single- and double-tag constructs were created (Figure 5). CaNDR1a was amplified by PCR using a high fidelity DNA polymerase according to the manufacturer's instructions ( $P f u-$ Turbo, Stratagene, La Jolla, CA, USA). The following primer couple was used for directly adding haemaglutinin (HA) and poly-histidine (His) sequences to the 5'- and 3'ends of the PCR products, respectively: CaNDR1-Forward 4, 5'-CACC ATG TAT CCC TAC GAC GTA CCA GAT TAT ATG TC AGA CCC CAG CAG CAG TGC-3' and CaNDR1-Reverse 3, 5'-CTA ATG GTG ATG GTG ATG GTG CAA CAG CAG AAC CAA GAA A-3'. The primers used for obtaining the single HA-tagged version were
CaNDR1-Forward 4 and CaNDR1-Reverse 2 (5'-CTA CAA CAG CAG AAC CAA GA-3'). PCR fragments were then subcloned into the pENTR-D/TOPO vector (Invitrogen, Cergy Pontoise, France) and sequenced. To get directional cloning, the underlined nucleotide sequence was added to the forward primers. Selected clones were digested with $M l u$-I restriction enzyme (R0198L, NEB, OZYME, Saint Quentin Yvelines, France) before overnight recombination with the binary vector pMDC32 [49] using the LR Clonase II kit (Invitrogen).

The N-terminally GFP6-tagged version was produced to examine the subcellular localization of CaNDR1a. PCR products were amplified, subcloned, sequenced and recombined with the binary vector pMDC43 [49] as described above. Primers used for the initial PCR step were as follows: CaNDR1-Forward 1, 5'-CACC ATG TCA GAC CCC AGC AGC AGT-3' and CaNDR1-Reverse 2. The vector used for in planta expression of the plasma membrane fluorescent marker (mCherry-tagged protein) was purchased from the Arabidopsis Biological Resource Center (ABRC) at Ohio State University (Stock \# CD31008) [36].

Final binary constructs were all sequenced (Genome Express) prior to transformation into Agrobacterium tumefaciens by heat shock or electroporation methods. Bacterial strain GV3101 was used for transformation of Arabidopsis plants by floral dipping according to [50]. Strain LBA1119 was used for transient expression experiments in tobacco plants.

\section{Pathogen challenge and growth curve assays}

The Pseudomonas syringae pv. tomato (Pst) strain $D C 3000$ and the isogenic strains expressing the bacterial effector proteins AvrRpt2 or AvrRps4 were provided by Dr. Jane Glazebrook (University of Minnesota) [51]. For pathogen challenges, bacteria were grown overnight at $28^{\circ} \mathrm{C}$ under mild shaking in liquid King B medium. Pst DC3000 bacteria were selected with rifampicin $(50 \mu \mathrm{g}$ $\mathrm{mL}^{-1}$ ); DC3000::AvrRpt2 and Pst DC3000::AvrRps4 with rifampicin and tetracycline $\left(10 \mu \mathrm{g} \mathrm{mL}^{-1}\right)$. Bacteria were collected by centrifugation and resuspended at $2 \times 10^{5}$ $\mathrm{CFU} \mathrm{mL} \mathrm{m}^{-1}$ in physiological water $(9 \mathrm{~g} \mathrm{NaCl} / \mathrm{L})$ prior to inoculation.

Progeny of Arabidopsis ndr1-1 T0 plants (ndr1-1:: CaNDR1a) were screened on half-strength Murashige and Skoog medium supplemented with $30 \mu \mathrm{g} \mathrm{mL}{ }^{-1}$ hygromycin. Transformation of individual resistant seedlings was confirmed by PCR using genomic DNA as the template and CaNDR1a-specific primers (CaNDR1-BglII and CaNDR1-BstEII). Homozygous single locus insertion lines were then isolated by following segregation of hygromycin-resistant plants in T2/T3 generations (Additional file 2). To assess $n d r 1-1$ complementation, three independent T3 lines displaying distinct expression 
levels for CaNDR1a (designated T3-1, T3-2 and T3-3) were challenged with Pst and in planta bacterial growth was followed over a four-day period (0,2 and $4 \mathrm{dpi})$. Wild type (Columbia, Col-0) and $n d r 1-1$ plants were also inoculated for comparison. Negative controls were infiltrated with physiological water. Half-leaves (6 to 7week-old plants) were hand-infiltrated with a $1-\mathrm{mL}$ needleless syringe. Two independent experiments that gave similar results were carried out. Each experiment comprised four replicates that were each performed by different individuals. In one replicate, each plant genotype (5 plants/genotype) was infiltrated with water or suspensions of Pst DC3000, Pst DC3000::AvrRpt2 or Pst DC3000::AvrRps4. Upon infiltration, plants were immediately placed in a tray covered with a plastic dome that was removed at 24 hours post-inoculation. Bacterial growth was monitored as follows. At each time point, two leaves (per plant) were harvested and ground with a mortar and pestle. The resulting mixture was serially diluted in sterile physiological water and plated onto solid King B medium supplemented with the appropriate antibiotics. The bacterial population was scored two days upon plating. Inoculation data were square-root transformed prior to ANOVA and subsequently subjected to the Student-Newman-Keuls multiple comparison test. When transformation failed to satisfy assumptions of normality and homoscedasticity, the non-parametric KruskalWallis test was used.

Hypersensitive and disease symptoms were also visually assessed in an independent experiment using higher concentrations of bacterial suspension $\left(2 \times 10^{7} \mathrm{CFU} \mathrm{mL}^{-1}\right)$ for infiltration. Samples from this experiment were also harvested for RT-qPCR analysis.

\section{RNA extraction, reverse transcription and real time quantitative-polymerase chain reaction}

Expression of AtNDR1 and CaNDR1a was measured as previously described [15] with the specific primers (Additional file 5) that were previously used [42]. Each assay was conducted in duplicate and included a negative control without template. The strong and constitutive actin gene (At3g18780) was chosen as internal control for normalization. Specificity of amplification was estimated by analyzing melting-temperature curves. Calculations for gene expression quantification were carried out using the comparative cycle-threshold method, as described previously [16].

\section{Agrobacterium tumefaciens-mediated transient expression}

Ten mL Agrobacterium cultures were grown overnight under mild shaking at $30^{\circ} \mathrm{C}$ in regular Luria-Bertani medium containing $25 \mu \mathrm{g} \mathrm{mL}-1$ rifampicin, and $50 \mu \mathrm{g} \mathrm{mL}^{-1}$ kanamycin when necessary. Bacteria were collected the following day by centrifugation. Pellets were resuspended in induction buffer (20 mM MES pH5.5, $10 \mathrm{mM} \mathrm{MgSO}$, $200 \mu \mathrm{M}$ acetosyringone) so that $\mathrm{OD}_{600 \mathrm{~nm}}$ of the solution reaches 0.5-0.6. Upon incubation at room temperature for 3 hours, the bacterial suspension was infiltrated onto the abaxial side of Nicotiana benthamiana leaves (4 to 6week-old plants) using a needleless syringe. Samples for western blot analysis and microscopy studies were harvested 2-3 dpi. Each experiment included a transformation control that was carried out by infiltrating a bacterial clone containing a 35S::uidA intron construct [52]. Histochemical beta-glucuronidase (GUS) staining was performed according to [53] using X-Gluc (5-bromo-4chloro-3-indolyl-beta-D-glucuronic acid) as substrate.

\section{Protein colocalization by confocal microscopy}

Subcellular localization of CaNDR1a was assessed by means of a transient expression system as described in the above sections. Overnight grown bacterial suspensions (GFP6-fused CaNDR1a and mCherry-fused marker) were individually induced and then mixed at 1:1 ratio before infiltration into tobacco leaves. Induction buffer and individual bacterial suspensions were also infiltrated as controls. Two to three days post infiltration, leaf disks $(1.2 \mathrm{~cm}$ diameter) were punched from the infiltrated area and directly observed with a LSM 510 Meta Zeiss upright laser scanning confocal microscope (Objective C-Apochromat 40X/1,2 water, $488 \mathrm{~nm}$ laser and 505-530 band-pass filter to GFP, $543 \mathrm{~nm}$ laser and 585-615 band-pass filter to mCherry). Spectral imaging was obtained with a $488 \mathrm{~nm}$ laser on the Meta detector. After Lambda stack acquisition between 500 and $640 \mathrm{~nm}$, the Linear Unmixing Function of confocal microscope discriminates between the fluorescence of GFP and mCherry in cells from reference spectra of these molecules obtained on leaves from GFP or mCherry plants (method of Emission Fingerprinting from Zeiss). The autofluorescence of chlorophyll was detected via a $650-\mathrm{nm}$ long pass filter. The images were coded green (GFP) or red (mCherry). The experiment was repeated five times (each replicate included at least two infiltrated leaves per plant and three independent plants).

\section{Plasma membrane purification}

To unambigously determine the subcellular localization of CaNDR1a proteins, the HA-tagged version of CaNDR1a was ectopically expressed in $N$. benthamiana leaves under conditions described above. Plasma membrane was prepared from infiltrated leaves at $2 \mathrm{dpi}$ and purified by two-phase PEG/dextran partitioning, as previously described [54]. The purity of PM fractions was checked by assessing the enrichment of the endogenous PM-resident protein PMA2. Western blotting conditions for PMA2 are described in the next section. 


\section{Protein extraction, SDS-PAGE and immunoblotting}

Protein samples were isolated by a two-step extraction protocol. Briefly, frozen leaf tissues ( $1 \mathrm{~g}$ fresh weight) were ground in ice-cold buffer $100 \mathrm{mM}, \mathrm{pH}$ 8.0, Tris buffer $(50 \mathrm{~mL})$ containing $1 \mathrm{mM}$ ethylenediamine tetraacetic acid, $1 \mathrm{mM}$ dithiothreitol and a protease inhibitor cocktail (1 tablet for $100 \mathrm{~mL}$ of buffer, Complete Mini, Roche Diagnostics, Meylan, France). Mixtures were centrifuged for $40 \mathrm{~min}$ at $12,000 \times \mathrm{g}$ at $4^{\circ} \mathrm{C}$. Protein concentration of supernatants was determined according to [55] using BSA as a standard. Overnight acetone precipitation was performed in order to concentrate samples. Upon western blot analysis, these crude extracts comprising the main soluble proteins appeared to contain neither of the two HA-tagged CaNDR1 versions. Mono- and polytopic membrane proteins were then extracted by resuspending the pellet in $400 \mu \mathrm{L}$ of extraction buffer in the presence of $2 \%$ (w/v) sodium dodecyl sulphate (SDS) (Additional file 4). Mixtures were warmed in a water bath at $70^{\circ} \mathrm{C}$ for $15 \mathrm{~min}$ and centrifuged for $25 \mathrm{~min}$ at $18,000 \times \mathrm{g}$ at room temperature. Pellets were discarded. Concentration of supernatant proteins was determined using the bicinchoninic acid assay (B-9643/C-2284, Sigma-Aldrich, Saint-QuentinFallavier, France) according to the manufacturer's instructions. Protein samples were loaded onto $12.5 \%$ polyacrylamide gels to be separated by SDS-PAGE. Proteins were transferred for immunoblot analysis by electroblotting onto nitrocellulose membranes $(0.45 \mu \mathrm{m}$, Hybond, GE Healthcare, Saclay, France) using X Cell II ${ }^{\mathrm{TM}}$ Blot Modules (Invitrogen). Successful transfer of proteins was checked by staining with a Ponceau S solution. Membranes were then incubated overnight at $4^{\circ} \mathrm{C}$ under mild shaking in a Tris-buffered saline solution containing $4 \%$ (w/v) dry milk (Cat. \# 170-6404, Bio-Rad, Marnes-la-Coquette, France) and $0.2 \%(\mathrm{v} / \mathrm{v})$ Tween 20. They were probed with antiHA-HRP (Cat.\# A00169, GenScript Corporation, Paris, France) or anti-(His) $)_{5}$-HRP (Cat.\# 34460, Qiagen) antibodies to detect epitope-tagged proteins. Both antibodies were used at a 1:2000 dilution.

Protein samples used as positive controls for His blots were prepared from Arabidopsis transgenic lines constitutively overexpressing a C-terminally His-tagged version of AtBI1 [56]. Seeds were kindly provided by Dr. Eric Lam (Biotechnology Center for Agriculture and the Environment, Rutgers University, USA). Proteins were extracted as described by the authors [56]. Freshly harvested leaves were directly ground in Laemmli buffer [57], warmed at $95^{\circ} \mathrm{C}$ for $5 \mathrm{~min}$ and centrifuged. The resulting supernatant was resolved by SDS-PAGE and blotted like other protein samples. The expected size of epitope-tagged AtBI1 is about $31 \mathrm{kDa}$.

Microsomal and plasma membrane samples were resolved by SDS-PAGE and transferred onto PVDF membranes for immunoblotting under the exact same conditions as other protein samples. HA-CaNDR1a detection was carried out as described above. When membranes were probed with antibodies raised against PMA2 (1:16.000 dilution) [58], a goat anti-rabbit antibody coupled to HRP (Cat.\# 656120, Invitrogen) was used as secondary antibody at a 1:2000 dilution. To test for the presence of HA-CaNDR1a, membranes probed with the PMA2-specific antiserum were then stripped off in the electrophoresis SDS-PAGE migration buffer in the presence of $\beta$-mercaptoethanol ( $28 \mathrm{mM}$ final concentration) at $50^{\circ} \mathrm{C}$ for 30 minutes. Membranes were then blocked and reprobed with anti-HA-HRP antibodies.

\section{Bioinformatic analysis}

Searches for CaNDR1 sequence homologs in the GenBank database were performed by means of Basic Local Alignment Search Tools, or BLAST [27], available online at the National Center for Biotechnology Information (http://ncbi.nlm.nih.gov/). Sequences were aligned using the ClustalX algorithm (version 2.0.10) [59] and further processed online at the BoxShade server (http://www.ch. embnet.org/software/BOX_form.html). The phylogenetic tree was built using Phylowin freeware using the neighbor-joining method [60]. Putative GPI-anchor attachment sites were identified using the Big-Pi Plant Predictor (http://mendel.imp.univie.ac.at/sat/gpi/plant_server.html) $[30,31]$. The occurence of signal peptides and transmembrane domains within primary amino-acid sequences was assessed using SignalP-3.0 (http://www. cbs.dtu.dk/services/SignalP/) [32,33]; that of glycosylation sites was predicted using NetNGlyc 1.0 (http://www.cbs. dtu.dk/services/NetNGlyc/). The freeware Mwcalc was used for calculations of the theoretical protein molecular weight and isoelectric point (http://sourceforge.net/ search/?q=mwcalc). Subcellular localization of proteins was predicted using the PSORTII program [34]. ChloroP1.1 [35] was also used for checking for the absence of putative chloroplast-targeting sequences in our proteins of interest. HarvEST ${ }^{\Theta}$ software that was used to identify the coffee RIN4-like protein is available online at http://harvest.ucr.edu/.

\section{Additional material}

Additional file 1: Full length alignment of CaNDR1a coding sequence with its Arabidopsis relatives. Alignment was performed as described in the legend of Figure 1. For sequence ID, see also the legend of Figure 1. The positions of the three NHL motifs within sequences are highlighted in red.

Additional file 2: T2 segregation results of CaNDR1a transgenic lines used in this study. Table showing the segregation of $\mathrm{Hyg}^{\mathrm{R}}$ and $\mathrm{Hyg}^{\mathrm{S}}$ phenotypes in $\mathrm{T} 2$ progeny from three $\mathrm{T} 1$ transgenic lines of Arabidopsis thaliana expressing CaNDR1a. The T3 lines that were selected for further work originated from $\mathrm{T} 2$ individuals that gave only $\mathrm{Hyg}^{\mathrm{R}}$ phenotypes upon selfing. 
Additional file 3: Ectopic expression of CaNDR1a in Arabidopsis ndr1-1 null mutant does not alter resistance to Pseudomonas syringae pv. tomato (DC3000::AvrRps4). Inoculation experiments were carried out as described in the 'Methods' section. A $2 \times 10^{-5} \mathrm{cfu} \mathrm{mL}^{-1}$ inoculum was used for this experiment, and the experiment was conducted twice. Bacterial growth was measured in planta over a fourday period. Means and standard errors (4 biological replicates) are shown for a representative experiment. Putative differences among leaf bacterial concentrations at T0 and $4 \mathrm{dpi}$ were statistically assessed by ANOVA of square-root transformed data followed by a SNK test $(\alpha<0.05)$. Data measured at $2 \mathrm{dpi}$ were analyzed using the non-parametric Kruskal-Wallis test. No significant differences in leaf bacterial concentration were observed among the Arabidopsis genotypes.

Additional file 4: Detergent is needed to extract CaNDR1a from tobacco leaves. CaNDR1a-tagged proteins that were transiently expressed in tobacco leaves were resolved by SDS-PAGE and subsequently transferred onto membrane by immunoblotting. Panel shows the scanned film corresponding to a representative membrane blotted with anti-HA serum (3 independent experiments). Ten $\mu \mathrm{g}$ of protein were loaded in each lane. Samples containing the main insoluble proteins extracted using SDS were loaded in lanes 1-4; those containing the main soluble proteins extracted without SDS were loaded in lanes 58. Protein extracts were prepared as described in the 'Methods' section. Lanes $1 \& 5$, samples prepared from tissues expressing the doublytagged CaNDR1a protein; lanes $2 \& 6$, samples prepared from leaves expressing the N-terminally HA-tagged CaNDR1a protein; lanes 3 \& 7 , negative controls, samples prepared from leaves infiltrated with the buffer that was used for resuspending Agrobacterium pellets; lanes 4 \& 8, negative controls, samples prepared from non-infiltrated leaves.

Additional file 5: Primers used for real-time quantitative PCR approach of gene expression in 35S::CaNDR1 A. thaliana transformed lines. Table with the name and sequence of primers used for RT-qPCR.

\section{List of abbreviations}

BiFC: bimolecular fluorescence complementation; ER: endoplasmic reticulum; EST: expressed sequence tag; GPI: glycosyl-phosphatidylinositol; HIN1: Harpin-induced gene 1; HR: Hypersensitive Response; NDR1: Non-race specific Disease Resistance 1; NHL: NDR1/HIN1-like; PCR: polymerase chain reaction; Pst: Pseudomonas syringae pv. tomato; R-gene: Resistance-gene; RACE: Rapid Amplification of CDNA ends; RIN4: RPM1-interacting protein 4.

\section{Acknowledgements}

The Arabidopsis null mutant ndr1-1 was a generous gift from Dr. Brian J. Staskawicz (University of California, Berkeley, CA, USA). Arabidopsis His-tagged Bax Inhibitor 1 lines were kindly provided by Dr. Eric Lam (Biotechnology Center for Agriculture and the Environment, Rutgers University, New Brunswick, NJ, USA). Construct CD3-1008 (mCherry plasma membrane marker) was purchased from the Arabidopsis Biological Resource Center (Ohio State University, Columbus, OH, USA). We wish to thank Dr. Jane Glazebrook (University of Minnesota, St. Paul, MN, USA) for providing the virulent and avirulent strains of Pseudomonas syringae pv. tomato used in this study (DC3000, DC3000::AvrRpt2 and DC3000::AvrRps4). We are grateful to Drs. Patrick Moreau and Su Melser for their contributions to the microscopy study. We also thank the Bordeaux Imaging Center (BIC, Université Bordeaux 2, UMS 3420 CNRS-US4 INSERM, Bordeaux, France). We also wish to warmly thank Drs Mark Diamond, and Jean-Luc Montillet for critically reading the manuscript, as well as Drs. Alison D Munson, Mark Diamond and William FJ Parsons for English editing. This work was partially supported through a bilateral cooperative agreement between France and Brazil (CAPES-COFECUB $n^{\circ}$ Sv 555/07). We declare no conflicts of interest with any work cited in this study.

\section{Author details}

${ }^{1}$ UMR 186 - IRD/CIRAD/UM2 Résistance des Plantes aux Bio-agresseurs, Institut de Recherche pour le Développement (IRD), BP64501, 34394 Montpellier Cedex 5, France. ${ }^{2}$ Centre d'Étude de la Forêt, Université Laval, Québec (QC), GIV 0A6, Canada. ${ }^{3}$ Plate-forme d'Histocytologie et d'Imagerie
Cellulaire Végétale, Biochimie et Physiologie Moléculaire des PlantesDéveloppement et Amélioration des Plantes, INRA-CNRS-CIRAD, TA96/02 Avenue Agropolis, 34398 Montpellier, France. ${ }^{4}$ Laboratoire de Biogenèse Membranaire (LBM), UMR 5200, CNRS-Université Victor Ségalen, Bordeaux 2, Case 92, 146 Rue Léo Saignat, 33076 Bordeaux Cedex, France.

\section{Authors' contributions}

JLC \& ASP carried out the bioinformatic analysis; JLC, ASP \& JE performed the cloning experiments; JLC, SM \& GC carried out the microscopy study; $J L C$ purified the plasma membrane and conducted the western blotting approach; JLC, JE, LB \& DF performed the pathogen inoculation and in planta growth assay; ASP conducted the RT-qPCR experiments; LB conducted the statistical analysis. JLC, LB \& DF designed/interpreted the experiments. JLC \& DF wrote the manuscript. All authors read and approved the final manuscript.

Received: 14 March 2011 Accepted: 24 October 2011

Published: 24 October 2011

\section{References}

1. Silva-Acuna R, Zambolim L, Berger RD: Incidence-severity relationships in the pathosystem Coffea arabica-Hemileia vastatrix. Plant Dis 1998, 83:186-188.

2. Silva $M C$, Várzea V, Guerra-Guimarães $L$, Azinheira $H G$, Fernandez D, Petitot $A S$, Bertrand B, Lashermes P, Nicole M: Coffee resistance to the main diseases: leaf rust and coffee berry disease. Braz J Plant Physiol 2006, 18:119-147.

3. Rodrigues CJ Jr, Bettencourt AJ, Rijo L: Races of the pathogen and resistance to coffee rust. Annu Rev Phytopathol 1975, 13:49-70.

4. Bettencourt AJ, Rodrigues CJ Jr: Principles and practice of coffee breeding for resistance to rust and other diseases. In Coffee Agronomy. Volume 4. Edited by: Clarke RJ, Macrae R. London and New York: Elsevier Applied Science Publishers; 1988:199-234.

5. Várzea VMP, Marques DV: Population variability of Hemileia vastatrix vs coffee durable resistance. In Durable resistance to coffee leaf rust. Edited by: Zambolim L, Zambolim E, Várzea VMP. Viçosa: Universidade Federal de Viçosa; 2005:53-74

6. Mayne WW: Physiologic specialization of Hemileia vastatrix B. \& Br. Nature $1932,129: 510$

7. Martins EMF, Moraes WBC: Development of Hemileia vastatrix in coffee plants with genetic and induced resistance. J Phytopathol 1996, 144:519-526

8. Silva MC, Nicole M, Guerra-Guimarães L, Rodrigues CJ Jr: Hypersensitive cell death and post-haustorial defense responses arrest the orange rust (Hemileia vastatrix) growth in resistant coffee leaves. Physiol Mol Plant Pathol 2002, 60:169-183.

9. Flor HH: Inheritance of pathogenicity in Melampsora lini. Phytopathology 1942, 32:653-669.

10. Jones JD, Dangl JL: The plant immune system. Nature 2006, 444:323-329.

11. Fernandez D, Tisserant E, Talhinhas P, Azinheira H, Vieira A, Petitot AS, Loureiro A, Poulain J, Silva MC, Da Silva C, Duplessis S: 454-pyrosequencing of Coffea arabica leaves infected by the rust fungus Hemileia vastatrix reveals pathogen-secreted proteins in planta and plant functions triggered in a late compatible plant-rust interaction. Mol Plant Pathol 2011

12. Morel JB, Dangl JL: The hypersensitive response and the induction of cell death in plants. Cell Death Differ 1997, 4:671-683.

13. Cacas JL: Devil inside: does plant programmed cell death involve the endomembrane system? Plant Cell Env 2010, 33:1453-1473.

14. Silva MC, Guerra-Guimaraes L, Loureiro A, Nicole M: Involvement of peroxidases in the hypersensitive reaction of coffee plants to orange rust (Hemileia vastatrix). Physiol Mol Plant Pathol 2008, 72:29-38.

15. Ramiro DA, Escoute J, Petitot AS, Nicole M, Maluf MP, Fernandez D: Biphasic haustorial differentiation of coffee rust (Hemileia vastatrix race II) associated with defence responses in resistant and susceptible coffee cultivars. Plant Pathol 2009, 58:944-955.

16. Ganesh D, Petitot AS, Silva MC, Alary R, Lecouls AC, Fernandez D: Monitoring of the early molecular resistance responses of coffee (Coffea arabica $L$.) to the rust fungus (Hemileia vastatrix) using real-time quantitative RT-PCR. Mol Plant Pathol 2006, 5:527-536.

17. Petitot AS, Lecouls AC, Fernandez D: Sub-genomic origin and regulation patterns of a duplicated WRKY gene in the allotetraploid species Coffea arabica. Tree Genet Genomes 2008, 3:379-390. 
18. Ramiro D, Jalloul A, Petitot AS, Grossi-de-Sa MF, Maluf M, Fernandez D: Identification of coffee WRKY transcription factor genes and expression profiling in resistance responses to pathogens. Tree Genet Genomes 2010, 6:767-781.

19. Fernandez D, Santos $P$, Agostini $C$, Bon MC, Petitot AS, C Silva M, GuerraGuimarães L, Ribeiro A, Argout X, Nicole M: Coffee (Coffea arabica L.) genes early expressed during infection by the rust fungus (Hemileia vastatrix). Mol Plant Pathol 2004, 5:527-536.

20. Century KS, Holub EB, Staskawicz BJ: NDR1, a locus of Arabidopsis thaliana that is required for disease resistance to both a bacterial and a fungal pathogen. Proc Natl Acad Sci USA 1995, 92:6597-6601.

21. Century KS, Shapiro AD, Repetti PP, Dahlbeck D, Holub E, Staskawicz BJ: NDR1, a pathogen-induced component required for Arabidopsis disease resistance. Science 1997, 278:1963-1965.

22. Coppinger P, Repetti PP, Day B, Dahlbeck D, Mehlert A, Staskawicz BJ: Overexpression of the plasma membrane-localized NDR1 protein results in enhanced bacterial disease resistance. Arabidopsis thaliana Plant J 2004, 40:225-237.

23. Aarts N, Metz M, Holub E, Staskawicz BJ, Daniels MJ, Parker JE: Different requirements for EDS1 and NDR1 by disease resistance genes define at least two $\mathrm{R}$ gene-mediated signaling pathways in Arabidopsis. Proc Natl Acad Sci USA 1998, 95:10306-10311.

24. Day B, Dahlbeck D, Staskawicz BJ: NDR1 interaction with RIN4 mediates the differential activation of multiple disease resistance pathways in Arabidopsis. Plant Cell 2006, 18:2782-2791.

25. Coaker G, Falick A, Staskawicz B: Activation of a phytopathogenic bacterial effector protein by a eukaryotic cyclophilin. Science 2005 308:548-550.

26. Altschul SF, Lipman DJ: Protein database searches for multiple alignments. Proc Natl Acad Sci USA 1990, 87:5509-5513.

27. Zheng MS, Takahashi H, Miyazaki A, Hamamoto H, Shah J, Yamaguchi I, Kusano T: Up-regulation of Arabidopsis thaliana NHL10 in the hypersensitive response to Cucumber mosaic virus infection and in senescing leaves is controlled by signalling pathways that differ in salicylate involvement. Planta 2004, 218:740-750.

28. Dörmann P, Gopalan S, He SY, Benning C: A gene family in Arabidopsis thaliana with sequence similarity to NDR1 and HIN1. Plant Physiol Biochem 2000, 38:789-796.

29. Schultz C, Gilson P, Oxley D, Youl J, Bacic A: GPI-anchors on arabinogalactan-proteins: implications for signalling in plants. Trends Plant Sci 1998, 3:426-431

30. Eisenhaber B, Bork P, Eisenhaber F: Post-translational GPI lipid anchor modification of proteins in kingdoms of life: analysis of protein sequence data from complete genomes. Protein Eng 2001, 14:17-25.

31. Eisenhaber B, Wildpaner M, Schultz CJ, Borner GH, Dupree P, Eisenhaber F: Glycosylphosphatidylinositol lipid anchoring of plant proteins. Sensitive prediction from sequence- and genome-wide studies for Arabidopsis and rice. Plant Physiol 2003, 133:1691-701

32. Nielsen $H$, Krogh A: Prediction of signal peptides and signal anchors by a hidden Markov model. In Proceedings of the Sixth International Conference on Intelligent Systems for Molecular Biology: 28 June-1 July 1998; Montréal. Edited by: Glasgow Jl, Littlejohn TG, Major F, Lathrop RH, Sankoff D, Sensen C. Menlo Park: AAAI Press; 1998:122-130.

33. Nielsen $H$, Engelbrecht J, Brunak S, von Heijne G: A neural network method for identification of prokaryotic and eukaryotic signal peptides and prediction of their cleavage sites. Int J Neural Syst 1997, 8:581-599.

34. Nakai K, Kanehisa M: A knowledge base for predicting protein localization sites in eukaryotic cells. Genomics 1992, 14:897-911.

35. Emanuelsson $\mathrm{O}$, Nielsen $\mathrm{H}$, von Heijne G: ChloroP, a neural network-based method for predicting chloroplast transit peptides and their cleavage sites. Protein Sci 1999, 8:978-984.

36. Nelson BK, Cai $X$, Nebenführ A: A multiple-color set of in vivo organelle markers for co-localization studies in Arabidopsis and other plants. Plant J 2007, 51:1126-1136.

37. Kim HS, Desveaux D, Singer AU, Patel P, Sondek J, Dangl JL: The Pseudomonas syringae effector AvrRpt2 cleaves its C-terminally acylated target, RIN4, from Arabidopsis membranes to block RPM1 activation. Proc Natl Acad Sci USA 2005, 102:6496-6501.

38. Takemoto D, Jones DA: Membrane release and destabilization of Arabidopsis RIN4 following cleavage by Pseudomonas syringae AvrRpt2. Mol Plant-Microbe Inter 2005, 18:1258-1268.
39. Lee SB, Ham BK, Park JM, Kim YJ, Paek KH: BnNHL18A shows a localization change by stress-inducing chemical treatments. Biochem Biophys Res Comm 2006, 339:399-406.

40. Chong J, Le Hananff G, Bertsch C, Walter B: Identification, expression analysis and characterization of defense and signaling genes in Vitis vinifera. Plant Physiol Biochem 2008, 46:469-481.

41. Johansson A, Staal J, Dixelius C: Early responses in the ArabidopsisVerticillium longisporum pathosystem are dependent on NDR1, JA- and ET-associated signals via cytosolic NPR1 and RFO. Mol Plant-Microbe Inter 2006, 19:958-969.

42. Azinheira HG, Silva MC, Medeira C, Maia I, Petitot AS, Fernandez D: Nonhost Resistance Responses of Arabidopsis thaliana to the Coffee Orange Rust Fungus (Hemileia vastatrix). Botany 2010, 88:621-629.

43. Thompson GA Jr, Okuyama H: Lipid-linked proteins of plants. Prog Lipid Res 2000, 39:19-39.

44. Knepper C, Savory E, Day B: Arabidopsis NDR1 is an integrin-like protein with a role in fluid loss and plasma membrane-cell wall adhesion. Plant Physiol 2011, 156:286-300.

45. Goyal K, Walton LJ, Tunnacliffe A: LEA proteins prevent protein aggregation due to water stress. Biochem J 2005, 388:151-157.

46. Belkhadir Y, Nimchuck Z, Hubert DA, Mackey D, Dangl JL: Arabidopsis RIN4 negatively regulates disease resistance mediated by RPS2 and RPM1 downstream or independent of the NDR1 signal modulator and is not required for the virulence functions of bacterial type III effectors AvrRpt2 or AvrRpm1. Plant Cell 2004, 16:2822-2835.

47. Etienne $H$, Anthony F, Dussert S, Fernandez D, Lashermes P, Bertrand B: Biotechnological applications for the improvement of coffee (Coffea arabica L.). In Vitro Cell Dev-Plant 2002, 38:129-138.

48. Albuquerque EVS, Cunha WG, Barbosa AEAD, Teixeira JB, Vianna GR, Cabral GB, Fernandez D, Grossi-de-Sa MF: Transgenic coffee fruits from Coffea arabica genetically-modified by bombardement. In Vitro Cell DevPlant 2009, 45:532-539.

49. Curtis MD, Grossniklaus U: A gateway cloning vector set for highthroughput functional analysis of genes in planta. Plant Physiol 2003, 133:462-469.

50. Clough SJ, Bent AF: Floral dip: a simplified method for Agrobacteriummediated transformation of Arabidopsis thaliana. Plant J 1998, 16:735-43.

51. Whalen MC, Innes RW, Bent AF, Staskawicz BJ: Identification of Pseudomonas syringae pathogens of Arabidopsis and a bacterial locus determining avirulence on both Arabidopsis and soybean. Plant Cell 1991, 3:49-59.

52. Hood E, Gelvin SB, Melchers LS, Hoekema A: New Agrobacterium helper plasmids for gene transfer to plants. Transgenic Res 1993, 2:208-218.

53. Jefferson RA, Kavanagh TA, Bevan MW: GUS fusions: beta-glucuronidase as a sensitive and versatile gene fusion marker in higher plants. $E M B O$ 1987, 6:3901-3907.

54. Mongrand S, Morel J, Laroche J, Claverol S, Carde JP, Hartmann MA Bonneu M, Simon-Plas F, Lessire R, Bessoules JJ: Lipid rafts in higher plants. Purification and characterization of triton X-100-insoluble microdomains from tobacco plasma membrane. J Biol Chem 2004 279:36277-36286.

55. Bradford WR: A rapid and sensitive method for the quantification of microgram quantities of protein utilizing the principle of protein-dye binding. Ann Biochem 1976, 72:248-254

56. Watanabe N, Lam E: BAX inhibitor-1 modulates endoplasmic reticulum stress-mediated programmed cell death in Arabidopsis. J Biol Chem 2008, 283:3200-3210.

57. Laemmli UK: Cleavage of structural proteins during the assembly of the head of bacteriophage T4. Nature 1970, 227:680-685.

58. Maudoux O, Batoko H, Oecking C, Gevaert K, Vandekerckhove J, Boutry M, Morsomme P: A plant plasma membrane $\mathrm{H}+-$ ATPase expressed in yeast is activated by phosphorylation at its penultimate residue and binding of 14-3-3 regulatory proteins in the absence of fusicoccin. $J$ Biol Chem 2000, 275:17762-17770.

59. Larkin MA, Blackshields G, Brown NP, Chenna R, McGettigan PA, McWilliam H, Valentin F, Wallace IM, Wilm A, Lopez R, Thompson JD, Gibson TJ, Higgins DG: Clustal W and Clustal X version 2.0. Bioinformatics 2007, 23:2947-2948.

60. Galtier N, Gouy M, Gautier C: SEAVIEW and PHYLO_WIN: two graphic tools for sequence alignment and molecular phylogeny. CABIOS 1996 12:543-548. 
61. Kierszniowska S, Seiwert B, Schulze WX: Definition of Arabidopsis sterolrich membrane microdomains by differential treatment with methylbeta-cyclodextrin and quantitative proteomics. Mol Cell Proteomics 2009, 8:612-623.

doi:10.1186/1471-2229-11-144

Cite this article as: Cacas et al:: Identification and characterization of the Non-race specific Disease Resistance 1 (NDR1) orthologous protein in coffee. BMC Plant Biology 2011 11:144.

Submit your next manuscript to BioMed Central and take full advantage of:

- Convenient online submission

- Thorough peer review

- No space constraints or color figure charges

- Immediate publication on acceptance

- Inclusion in PubMed, CAS, Scopus and Google Scholar

- Research which is freely available for redistribution

Submit your manuscript at www.biomedcentral.com/submit
C) Biomed Central 